\title{
Boosting High-Performance in Lithium-Sulfur Batteries via Dilute Electrolyte
}

\author{
Feixiang Wu, ${ }^{*}, \dagger$ Fulu Chu, ${ }^{\dagger}$ Guillermo A. Ferrero, ${ }^{\ddagger}$ Marta Sevilla, ${ }^{\ddagger}$ \\ Antonio B. Fuertes, ${ }^{\ddagger}$ Oleg Borodin, $\perp$ Yan Yu, ${ }^{*},,$, and Gleb Yushin ${ }^{*}, \nabla$ \\ † School of Metallurgy and Environment, Engineering Research Center of the \\ Ministry of Education for Advanced Battery Materials, Central South \\ University, Changsha 410083 P. R. China. \\ ¥ Instituto Nacional del Carbón (CSIC), Fco. Pintado Fe 26, Oviedo 33011, \\ Spain \\ $\perp$ Battery Branch, Sensors and Electron Devices Directorate, US Army \\ Research Laboratory, Adelphi, MD 20783, USA \\ $\S$ Hefei National Laboratory for Physical Sciences at the Microscale Department \\ of Materials Science and Engineering, CAS Key Laboratory of Materials for \\ Energy Conversion, University of Science and Technology of China, Hefei, \\ Anhui 230026, P. R. China \\ $\xi$ Dalian National Laboratory for Clean Energy (DNL), Chinese Academy of \\ Sciences (CAS), Dalian 116023, P. R. China \\ $\nabla$ School of Materials Science and Engineering, Georgia Institute of Technology, \\ Atlanta, GA 30332, USA.
}




\begin{abstract}
Polysulfide shuttle effects, active material losses, formation of resistive surface layers and continuous electrolyte consumption create a major barrier for the lightweight and low-cost lithium-sulfur (Li-S) battery adoption. Tuning electrolyte composition by using additives and most importantly by substantially increasing electrolyte molarity was previously shown to be one of the most effective strategies. Contrarily, little attention has been paid to dilute and superdiluted $\mathrm{LiTFSI} / \mathrm{DME} / \mathrm{DOL} / \mathrm{LiNO}_{3}$ based-electrolytes, which have been thought to aggravate the polysulfide dissolution and shuttle effects. Here we challenge this conventional wisdom and demonstrate outstanding capabilities of a dilute (0.1 mol L-1 of LiTFSI in DME/DOL with $1 \mathrm{wt}$ \% $\mathrm{LiNO}_{3}$ ) electrolyte to enable better electrode wetting, greatly improved high-rate capability and stable cycle performance for high sulfur loading cathodes and low electrolyte/sulfur ratio in Li-S cells. Overall, the presented study shines light on the extraordinary ability of such electrolyte systems to suppress short-chain polysulfide dissolution and polysulfide shuttle effects.
\end{abstract}

Keywords: Li-S; Super-Diluted; Electrolyte; Sulfur Cathode; Battery

\title{
INTRODUCTION
}

As the world faces a rapidly growing demand to move to renewable energy sources and to drastically reduce carbon emissions, battery technologies need to offer improved energy storage for electric cars, busses and trucks, drones, electric planes and the grid. ${ }^{1-4}$ For large-scale transportation and many mobile applications, fabrication of lightweight and stable batteries is particularly important, while reducing cathode toxicity remains imperative for low environmental impact.2,5 The lithium-sulfur (Li-S) battery system offers a combination of a very low weight, low toxicity, low cost, and high specific energy. With one of the highest theoretical capacities $(1675 \mathrm{mAh} / \mathrm{g})$ of any conversiontype cathode, the pursuit of long-lasting and stable Li-S batteries remains a global research focus for the last decade. 2, 3, 6-8 
In the Li-S conversion chemistry studies, the most commonly used electrolyte comprises $\sim 1 \mathrm{M}$ lithium bis(trifluoromethanesulfonyl)imide (LiTFSI) salt solution in distilled dimethoxyethane (DME):1,3-dioxolane (DIOX) (1:1, v:v) solvent with 1 2 wt \% of $\mathrm{LiNO}_{3}$ additive. ${ }^{9-11}$ The reduction of $\mathrm{S}$ typically proceeds through a formation of a series of polysulfide species, which are for the most part soluble in common organic solvents and electrolytes. Successful commercialization of Li-S batteries is severely hindered by polysulfide shuttle effects and strict requirements of low electrolyte/sulfur (E/S: $\mu \mathrm{L} / \mathrm{mg}$ ) ratio and high $S$ mass loading cathodes in commercial cells. ${ }^{12-14}$ The polysulfide dissolution and the migration of redox - active species cause the loss of active $S$ and thus reversible capacity, self-discharge, low Coulombic efficiency (CE) and unfavorable layer formation on both $S$ cathode and Li anode that induces resistance growth. The lack of a passivating surface layer results in the electrolyte being continuously consumed until it is exhausted to the battery death. To achieve high energy densities of Li-S batteries, the simultaneous employment of rather low E/S ratio and high $S$ mass loading cathode become essential. ${ }^{13-15}$ Such requirements further increase the demands for improved cathode stability against shuttle effects, better electrolyte wetting, faster reaction kinetics and even more stable surface layers to achieve long cycle life and reasonable charging rates.

In previous studies, composite particle design $2,16-22$ and electrolyte modification ${ }^{7,23-25}$ have been the most effective complementary strategies to overcome known challenges. Porous carbons and polar inorganic compounds with different nano-architectures have been widely employed as $\mathrm{S}$ or $\mathrm{Li}_{2} \mathrm{~S}$ hosts. ${ }^{21,26-33}$ Optimizations of both liquid and solid electrolytes have proved to be particularly effective in enhancing the cyclability of a broad range of $\mathrm{S} / \mathrm{Li}_{2} \mathrm{~S}$ cathodes. ${ }^{23,34-37}$

So far, organic liquid electrolytes and their fundamental studies dominate the mainstream due to their high ionic conductivity. To protect active material from shuttle effects, functional additives (or Li salts) have been reported to induce in-situ formation of solid electrolyte interphase to enhance stability and performance of $\mathrm{S} / \mathrm{Li}_{2} \mathrm{~S}$ cathodes. ${ }^{25,38-41}$ In addition, $-\mathrm{NH}$ or $\mathrm{NH}_{4}{ }^{+}$based additives in electrolytes have been reported to adjust the solubility $\mathrm{Li}_{2} \mathrm{~S}$ or $\mathrm{Li}_{2} \mathrm{~S}_{2}$, aiming 
to improve the conversion reaction kinetics. ${ }^{42,43}$ For preventing the polysulfide shuttle in Li-S cells, a novel electrolyte solution of $0.2 \mathrm{~mol} \mathrm{~L}^{-1}$ containing lowion-pairing salt $\left(\mathrm{Li}\left[\mathrm{Al}(\mathrm{Ohfip})_{4}\right]\right)$ and a triflamide solvent (N,N-dimethyl triflimide, DMT) have been developed. ${ }^{44}$ In addition, $0.2 \mathrm{~mol} \mathrm{~L}^{-1}$ solution of novel salt $\mathrm{Li}\left[\mathrm{B}(\mathrm{OTfe})_{4}\right]$ in standard solvents (DME/DOL) has been investigated in Li-S cells. ${ }^{45}$ Since 2013 , ultra-saturated salt-solvent mixtures have become a popular avenue to combat the polysulfide dissolution due to smaller fraction of solvent molecules not participating in $\mathrm{Li}^{+}$and $\mathrm{TFSI}^{-}$solvation and available for solvating the polysulfides. ${ }^{46-49}$ However, such electrolytes typically display high viscosity, low $\mathrm{Li}^{+}$mobility, poor wetting on $\mathrm{S}$ cathodes, resulting in low capacity utilization, low rate capability and reduced practically attainable energy density, particularly for low E/S ratio and high mass loading cathodes. ${ }^{9,} 50$ In contrast, one literature at very recent showed that $0.1 \mathrm{M} \sim 0.5 \mathrm{M} \mathrm{LiTFSI}$ with $0.4 \mathrm{M} \mathrm{LiNO} 3$ in DME/DOL demonstrated better rate capability and smaller voltage hysteresis, but worse cycle stability in Li-S cells than those in $1 \mathrm{M}$ standard electrolytes. ${ }^{9}$ Overall, especially for the standard electrolyte system of $\mathrm{LiTFSI} / \mathrm{LiNO}_{3} / \mathrm{DME} / \mathrm{DOL}$, little attention has been paid to dilute and ultra-dilute electrolytes, which have been thought to aggravate the polysulfide dissolution and shuttle effects because according to a solution theory a higher fraction of free solvents for solvation should result in stronger and faster solvency.

Here we challenge this conventional wisdom and demonstrate outstanding capabilities of dilute $\left(0.1 \mathrm{~mol} \mathrm{~L}^{-1}\right)$ electrolytes to enable better electrode wetting, greatly improved high-rate capability and stable cycle performance for high active mass loading $S$ cathodes and low E/S ratio in Li-S cells. We prepare such dilute $(0.1 \mathrm{M})$ electrolyte using LiTFSI salt and solvents (DME/DOL, 1:1) with 1 wt.\% $\mathrm{LiNO}_{3}$ and yet attain rather unique and unexpected properties. Using a powerful combination of post-mortem analyses and numerical simulations we explain our discovery of abnormal reductions in short-chain polysulfide dissolution and migration of soluble sulfur species in dilute electrolytes. As additional benefits, the dilute electrolytes are less expensive, lighter, less viscous than both standard $1 \mathrm{M}$ and high-M electrolytes, which may open new avenues for the exploration and overcoming challenges of other battery systems. 


\section{RESULTS AND DISCUSSION}

Carbon capsule-sulfur (CC-S) composites were selected as cathode material in our studies. More details including BET surface area, element mapping, $S$ content and phase are discussed in the supporting information (Fig.S1-S4). Note that $S$ in such electrodes exhibits a direct contact with liquid electrolytes and thus should form polysulfides during cycling and induce polysulfide dissolution and shuttle. ${ }^{30,51}$ The impact of electrolyte molarity was studied using coin cells with Li metal anode and LiTFSI salt concentrations ranging from ultra-concentrated (up to $5 \mathrm{M}$ ) to regular $(1 \mathrm{M})$ to dilute $(0.1 \mathrm{M})$ compositions in DME/DOL with $1 \mathrm{wt}$ \% $\mathrm{LiNO}_{3}$. Rate tests conducted at various current densities (from $0.1 \mathrm{C}$ to $2 \mathrm{C}$ ) on medium loading $\left(2 \mathrm{mgs}_{\mathrm{s}} \mathrm{cm}^{-2}\right)$ cathodes allowed us to evaluate changes in the ionic polarization as a function of electrolyte composition (Fig. 1).

The shape of the discharge / charge profiles reveal the voltage curves typical for Li-S chemistry with two plateaus corresponding to $\mathrm{S}_{8} \rightarrow \mathrm{Li}_{2} \mathrm{~S}_{4}$ (the $1^{\text {st }}$, shorter, higher voltage plateau) and $\mathrm{Li}_{2} \mathrm{~S}_{4} \rightarrow \mathrm{Li}_{2} \mathrm{~S}$ (the $2^{\text {nd }}$, longer, lower voltage plateau). ${ }^{52}$ In a standard $1 \mathrm{M}$ electrolyte, the $\mathrm{S}$ cathodes displayed high capacity $\left(1265 \mathrm{mAh} \cdot \mathrm{g}^{-1}\right)$ and high $2^{\text {nd }}$ galvanostatic discharge voltage plateau $(\sim 2.1 \mathrm{~V}$ vs. $\mathrm{Li} / \mathrm{Li}^{+}$; voltage hysteresis $\sim 0.15 \mathrm{~V}$ ) at a slow rate of $\mathrm{C} / 10$, gradually reducing to $\sim 50 \%$ of the initial capacity $\left(650 \mathrm{mAh} \cdot \mathrm{g}^{-1}\right.$ at $2 \mathrm{C}$ ) and $\sim 1.8 \mathrm{~V} \mathrm{vs}$. $\mathrm{Li}^{\prime} / \mathrm{Li}^{+}$(voltage hysteresis of $\sim 0.65 \mathrm{~V}$ ) at $2 \mathrm{C}$ (Fig. 1a), indicating a limited rate performance, as may be expected for relatively thick and unprotected from dissolution/shuttle effects CC-S cathodes. Increasing electrolyte concentration to $2 \mathrm{M}$ (Fig. 1b), 3M (Fig. S5) and finally to 5M (Fig. 1c) noticeably reduced capacity utilization and increased voltage hysteresis at high rates. In fact, cells with concentration electrolytes showed very low specific capacity $\left(100-300 \mathrm{mAh} \cdot \mathrm{g}^{-1}\right)$ at $1 \mathrm{C}$ and even smaller (50-100 $\left.\mathrm{mAh} \cdot \mathrm{g}^{-1}\right)$ at $2 \mathrm{C}$ (Fig. 1b-2c). We could not even distinguish two discharge plateaus in such cells at $1 \mathrm{C}-2 \mathrm{C}$ rates, indicating rather poor reaction kinetics in concentrated electrolytes. Quite remarkably, reducing LiTFSI salt concentration to $0.1 \mathrm{M}$ resulted in both high accessible capacity and dramatically improved rate performance $(\sim 75 \%$ of the initial capacity or $956 \mathrm{mAh} \cdot \mathrm{g}^{-1}$ at $1 \mathrm{C}$ and $828 \mathrm{mAh} \cdot \mathrm{g}^{-1}$ at $2 \mathrm{C}$ ) with noticeably smaller distortions of the voltage curves and smaller voltage hysteresis growth with 
increasing rates (voltage hysteresis of only $\sim 0.4 \mathrm{~V}$ at $2 \mathrm{C}$ ) when compared to cells with $1 \mathrm{M}, 2 \mathrm{M}, 3 \mathrm{M}$ and $5 \mathrm{M}$ electrolytes (Fig. 1a-1e).

Besides sufficiently high rates, here again, low molarity electrolytes showed superior performance (Fig. 1e-1f). When cells were cycled at moderate $\mathrm{C} / 2$ rate for 200 cycles, both $1 \mathrm{M}$ and $2 \mathrm{M}$ electrolytes resulted in a visible capacity degradation to $\sim 65 \%$ within 200 cycles, providing a discharge capacity of just $\sim 600 \mathrm{mAh} \mathrm{g}^{-1}$ at the $200^{\text {th }}$ cycle. In concentrated electrolytes of $3 \mathrm{M}$ and $5 \mathrm{M}$, the cells demonstrated rather low capacity utilization (100-200 $\left.\mathrm{mAh} \cdot \mathrm{g}^{-1}\right)$ at $\mathrm{C} / 2$ due to limited reaction kinetics. However, in $0.1 \mathrm{M}$ electrolyte, the cell showed outstanding capacity stability, displaying $\sim 95 \%$ capacity retention after 200 cycles ( $970 \mathrm{mAh} \mathrm{g}^{-1}$ at the $200^{\text {th }}$ cycle), and suggesting that polysulfide shuttle and irreversible $\mathrm{Li}_{2} \mathrm{~S}$ deposition on the $\mathrm{Li}$ anode and resistance growth was miraculously minimized. As shown in Fig. S6, compared to $1 \mathrm{M}$ electrolyte, the cell using dilute $(0.1 \mathrm{M})$ electrolyte displays higher CE within 200 cycles. In order to further investigate the difference in the cycling stability behavior, the changes in the voltage profiles within 200 cycles are shown in Fig. 1g-1i and S5. Clearly, there are very minimal changes in the profiles of the cell with $0.1 \mathrm{M}$ electrolyte during 200 cycles (Fig. 1g). In contrast, the cell with $1 \mathrm{M}$ or $2 \mathrm{M}$ electrolyte shows significant changes in the voltage profile and a noticeably higher voltage hysteresis, indicating the serious polysulfide shuttle effects in common 1 2M electrolytes (Fig. 1h and S7a). While using more concentrated $3 \mathrm{M}$ and $5 \mathrm{M}$ electrolytes, the cells demonstrate rather low capacity, and disappearing of $2^{\text {nd }}$ discharge plateaus because of huge voltage hysteresis beyond working voltage window (Fig. $1 \mathrm{i}$ and S7b).

Post-mortem analysis of the electrodes revealed a dramatic impact of salt concentration on the morphologies of both $\mathrm{Li}$ anodes and CC-S cathodes. Compared to the SEM images of a fresh CC-S cathode in Fig. S8a, the surface of cycled CC-S electrode in $1 \mathrm{M}$ electrolyte becomes rough and fully covered by a thick surface layer containing re-precipitated particles (Fig.2a), as could be expected from prior-art studies. ${ }^{25,39}$ In addition, the cycled Li metal anode in $1 \mathrm{M}$ electrolyte show a rough and highly uneven surface covered with nonuniform solid electrolyte interphase (SEI) layer (Fig.S8c) comprising precipitated $\mathrm{Li}_{2} \mathrm{~S}$ 
nanoparticles and large Li metal grains emerging through the $\mathrm{SEI} / \mathrm{Li}_{2} \mathrm{~S}$ layer (Fig. 2c). The dissolved and re-precipitated polysulfides are known to be associated with the formation of $\mathrm{Li}_{2} \mathrm{~S}$ in the anode (Fig. 2c), the losses of active material and capacity decay (Fig. 1f) as well as the increased cell resistance (Fig. 2e). ${ }^{7,} 52$ In sharp contrast, the CC-S cathode cycled in $0.1 \mathrm{M}$ electrolyte shows only marginal surface changes and absence of unfavorable particles (or layer) after cycling (Fig. $2 \mathrm{~b}$ and S8b), in agreement with the previously discussed cycling stability results (Fig. 1f). Meanwhile, the Li foil cycled in a $0.1 \mathrm{M}$ electrolyte exhibits a very smooth surface morphology with homogeneous large Li grains and thin and dense SEI layer without any visible precipitates and vertical dendrites (Fig. $2 \mathrm{~d}$ and S8d), confirming that the polysulfide shuttle effects have been successfully suppressed. These findings are also consistent with no visible increase of charge-transfer resistance in the $0.1 \mathrm{M}$ electrolyte cell (Fig. 2f). The cycled electrolytes of both $0.1 \mathrm{M}$ and $1 \mathrm{M}$ were collected to identify possible color changes (Fig. S9). As expected, the color of cycled $1 \mathrm{M}$ benchmark electrolyte turned into visible yellow that is much deeper than the color of cycled $0.1 \mathrm{M}$ electrolyte, also indicating that the polysulfide shuttle and $\mathrm{S}$ loss were noticeably reduced in the $0.1 \mathrm{M}$ electrolyte.

Other important considerations for practical cells are attaining favorable cell characteristics for low E/S ratio and high S loadings. As such, several cells with different $S$ mass loadings and $E / S$ ratios were tested in dilute $(0.1 \mathrm{M})$ electrolyte (Fig. S10). Using an average E/S ratio of $15 \mu \mathrm{L} \cdot \mathrm{mg}^{-1}$ and active mass loading of $3.8 \mathrm{mg} \cdot \mathrm{cm}^{-2}$, the cells showed promising capacity utilizations with a discharge capacity of 1038,920 and $779 \mathrm{mAh} \cdot \mathrm{g}^{-1}$ at $0.1 \mathrm{C}, 0.2 \mathrm{C}$ and $0.5 \mathrm{C}$ rates, respectively (Fig. S10a). When cycled at $0.5 \mathrm{C}$ for over 300 cycles, the cell showed a capacity retention of $92 \%\left(718 \mathrm{mAh} \cdot \mathrm{g}^{-1}\right.$ at $300^{\text {th }}$ cycle) (Fig. S10b). Increasing the active mass loading to $5.2 \mathrm{mg} / \mathrm{cm}^{2}$ and reducing the $\mathrm{E} / \mathrm{S}$ ratio to $8 \mu \mathrm{L} \cdot \mathrm{mg}^{-1}$ (Fig. S10c and d) resulted in discharge capacities of 896,830 and $716 \mathrm{mAh} \cdot \mathrm{g}^{-1}$ at $0.1 \mathrm{C}, 0.2 \mathrm{C}$ and $0.5 \mathrm{C}$, respectively, and a capacity retention of 
$97 \%$ within 100 cycles at $0.5 \mathrm{C}$. Compared to previous studies on fully unprotected $S$ cathodes with high loadings, ${ }^{13,53}$ the rate capability at $0.5 \mathrm{C}$, small voltage hysteresis and cycle stability produced by the high active mass loading (up to $5.2 \mathrm{mg} / \mathrm{cm}^{2}$ ) and moderate $\mathrm{E} / \mathrm{S}$ ratio (down to $8 \mu \mathrm{L} \cdot \mathrm{mg}^{-1}$ ) in the dilute $(0.1 \mathrm{M})$ electrolyte are clearly very promising.

In order to reveal the underlying mechanism(s) for superior performance of dilute electrolytes in Li-S batteries, we analyzed physical properties, interactions with polysulfides and conducted molecular dynamics (MD) simulations. When compared to standard $(1 \mathrm{M})$ and concentrated $(2 \mathrm{M}, 3 \mathrm{M}, 5 \mathrm{M}$, 7M) electrolytes (some of which are often called "solvent-in-salt" electrolytes), an dilute $(0.1 \mathrm{M})$ electrolyte utilizes much less salt and offers a smaller density (Fig. 3a and c), which are beneficial for achieving low cost and higher specific energy in Li-S batteries. Through the ionic conductivity studies of $0.1,1,3,5$, and $7 \mathrm{M}$ electrolytes, electrolytes with different molarities indeed display different ionic conductivities that are affected by both ion concentration and ionic mobility. As shown in Fig.3b, the ionic conductivity of $0.1 \mathrm{M}$ electrolyte $(1.78 \mathrm{mS} / \mathrm{cm})$ is lower than that of $1 \mathrm{M}(12.16 \mathrm{mS} / \mathrm{cm})$. Since the rate performance of cell is determining by $\mathrm{Li}^{+}$solvation/dissociation and the subsequent $\mathrm{Li}^{+}$migration, ${ }^{54}$ both the electrolyte viscosity and wettability of the electrode by the electrolyte are important factors for cell manufacturing rate and cell cycling rate. We investigated the impact of salt concentration on electrolyte viscosity and the CC-S cathode wetting (Fig. $3 \mathrm{~d}$ and e). The dilute (0.1M) electrolyte enables extremely small viscosity $(\sim 0.6 \mathrm{cP}$ or $\mathrm{mPa} \cdot \mathrm{s})$, which correlates with high Li ion mobility (see Table S2). The wetting of the CC-S cathode by this $(0.1 \mathrm{M})$ electrolyte is also excellent (Fig. $3 \mathrm{~d})$ with the contact angle of mere $15.8^{\circ}$ at $0.06 \mathrm{sec}$, while standard $1 \mathrm{M}$ and moderately concentrated $3 \mathrm{M}$ electrolytes display contact angles of $24.1^{\circ}$ and $72.1^{\circ}$, respectively. The good wetting, low viscosity and high Li ion mobility of this dilute electrolyte may explain fast the $\mathrm{Li}^{+}$transport at the solid-liquid interface 
and higher capacity utilization and lower voltage hysteresis at high $\mathrm{C}$ rates (Fig. 2).

MD simulations of short-chain polysulfide $\mathrm{Li}_{2} \mathrm{~S}_{2}$ placed in a dilute $(0.1 \mathrm{M})$ electrolyte show a very strong aggregation of $\mathrm{Li}_{2} \mathrm{~S}_{2}$ (Fig. $4 \mathrm{a}$ and Fig.S11), suggesting a very low $\mathrm{Li}_{2} \mathrm{~S}_{2}$ polysulfide solubility. ${ }^{11} \mathrm{LiTFSI}$ is fully dissociated in low LiTFSI concentrations, with TFSI- anions being well dispersed (Fig. 4a) while the $\mathrm{Li}^{+}$cations being strongly bound to the $\mathrm{S}_{2}^{(2-)}$ anions (Fig. S12a), thus bridging the $\mathrm{Li}_{2} \mathrm{~S}_{2}$ into a well-defined domain (Fig. 4a) that indicates a strong phase separation of short-chain polysulfide in the electrolyte. Increasing the LiTFSI salt concentration from $0.1 \mathrm{M}$ to $1 \mathrm{M}$ increases Li-TFSI aggregation (see higher peak for $\mathrm{Li}-\mathrm{O}(\mathrm{TFSI})$ in Fig. S12). As a result, the $\mathrm{TFSI}^{-}$anions become more frequently binding to $\mathrm{Li}^{+}$and thus screening the desired $\mathrm{Li}^{+}$and polysulfide interactions. This screening prevents bridging and agglomeration of the $\mathrm{Li}_{2} \mathrm{~S}_{2}$ into separate domains and result in the $\mathrm{Li}_{2} \mathrm{~S}_{2}$ becoming much more evenly distributed in the simulation box (Fig. 4b) with a much weaker intermolecular S...S peak for short-chain polysulfides (Fig. 4d). Further increase of the LiTFSI salt concentration to $3 \mathrm{M}$ makes less solvent available to solvate both $\mathrm{Li}_{2} \mathrm{~S}_{2}$ and LiTFSI, resulting in an expected (from prior art studies) increased aggregation of sulfide anions (reduced polysulfide $\mathrm{Li}_{2} \mathrm{~S}_{2}$ dissolution) and the increased $\mathrm{S}$...S first peak compared to $1 \mathrm{M}$ LiTFSI electrolyte (Fig. 4c and 4d). However, the value of this peak for $3 \mathrm{M}$ electrolyte remains significantly smaller than that for $0.1 \mathrm{M}$ electrolyte, highlighting superior performance of $0.1 \mathrm{M}$ electrolyte in terms of increased short-chain polysulfide agglomeration and thus reduced $\mathrm{S}$ loss and shuttle effects during $2^{\text {nd }}$ discharge voltage plateau (solid to solid conversion reaction). The $1 \mathrm{M} \mathrm{LiTFSI}$ is the most vulnerable to polysulfide shuttle effects due to a combination of two factors: (i) sufficient screening of $\mathrm{Li}_{2} \mathrm{~S}_{2}$ by TFSlanions and (ii) availability of free solvent to solvate ions. Interestingly, aggregation of long-chain $\mathrm{Li}_{2} \mathrm{~S}_{4}$ was less dependent on the LiTFSI concentration as shown in Fig.S13, showing similar solubility of long-chain 
polysulfides in both $0.1 \mathrm{M}$ and $1 \mathrm{M}$ electrolytes. According to previous reports, the formation of liquid long-chain polysulfides $\left(\mathrm{S}_{8}{ }^{2-}, \mathrm{S}_{6}{ }^{2-}\right.$ and $\left.\mathrm{S}_{4}{ }^{2-}\right)$ can effectively increase the active sulfur utilization via enhancing the reaction kinetics of solidliquid and liquid-solid sulfur conversion (offering more and short pathways for ion and electron transports). ${ }^{11,55-57}$ Therefore, no significant difference of longchain polysulfides dissolution can explain the similar capacity utilizations at small $\mathrm{C}$ rates $(0.1 \mathrm{C}-0.5 \mathrm{C})$ in both $0.1 \mathrm{M}$ and $1 \mathrm{M}$ electrolytes in Fig. $1 \mathrm{a}$ and $\mathrm{d}$. As another explanation, fundamentally the lattice energy of the salt $\mathrm{Li}_{2} \mathrm{~S}_{2}$ is higher than that of $\mathrm{Li}_{2} \mathrm{~S}_{4}, \mathrm{Li}_{2} \mathrm{~S}_{6}$ and $\mathrm{Li}_{2} \mathrm{~S}_{8}$ (larger anion size). Thus, the long-chain polysulfides $\left(\mathrm{Li}_{2} \mathrm{~S} x, x=4,6,8\right)$ have higher solubilities in DOL/DME. Yet, the situation changes if one compares the solvating properties of the 0.1 and $1.0 \mathrm{M}$ LiTFSI electrolytes. Although the solvents are same (DOL/DME), the ionic strength of the solution, which corresponds to the capacity to dissolve smaller ions with higher lattice energies, increases from 0.1 to $1.0 \mathrm{M}$. This easily explains the reduced solubility of the smaller $\mathrm{Li}_{2} \mathrm{~S}_{2}$ compound in the lower ionic strength electrolyte $(0.1 \mathrm{M})$. In addition, this explanation is in agreement with the entire MD-simulation.

Moreover, despite lower viscosity for $0.1 \mathrm{M} \mathrm{LiTFSI}+0.5 \mathrm{M} \mathrm{Li}_{2} \mathrm{~S}_{2}$ electrolyte compared to $1 \mathrm{M} \mathrm{LiTFSI}+0.44 \mathrm{M} \mathrm{Li}_{2} \mathrm{~S}_{2}$ electrolyte the $\mathrm{S}_{2}{ }^{(2-)}$ self-diffusion coefficient is factor of two lower for the more dilute electrolyte due to much stronger aggregation of $\mathrm{Li}_{2} \mathrm{~S}_{2}$ in the former resulting in reduced mobility of $\mathrm{S}_{2}{ }^{(2-)}$. When both $\mathrm{Li}_{2} \mathrm{~S}_{2}$ and $\mathrm{Li}_{2} \mathrm{~S}_{4}$ species are present in electrolyte simultaneously the $\mathrm{Li}_{2} \mathrm{~S}_{4}$ species bind to $\mathrm{Li}_{2} \mathrm{~S}_{2}$ and their aggregates as shown in Fig. 4(e-f) resulting in lower mobility of $\mathrm{S}_{4}^{-}$when $\mathrm{Li}_{2} \mathrm{~S}_{2}$ aggregates are present, i. e. in dilute electrolytes.

In Fig. 5, the lithium polysulfide dissolution experiments were conducted in pure solvent, dilute $(0.1 \mathrm{M})$, standard $(1 \mathrm{M})$ and concentrated $(3 \mathrm{M})$ electrolytes to see the color changes with time (which are indicative of the formation, dissolution and diffusion of mixed long-chain polysulfides). Similar to previous 
results (Fig. 4) and prior art studies, ${ }^{47}$ the lithium polysulfide formation, dissolution and diffusion into the bulk of the electrolyte are somewhat limited in concentrated electrolytes (3M electrolyte in Fig. 5) when compares with $1 \mathrm{M}$ electrolyte. When do the comparison among the results in pure solvents, $0.1 \mathrm{M}$ and $1 \mathrm{M}$ solutions, the observed deep yellow color indicates the rapid formation of long-chain polysulfides (might be the mixture of $\mathrm{S}_{8}{ }^{2-}, \mathrm{S}_{6}{ }^{2-}$ and $\mathrm{S}_{4}{ }^{2-}$ ) at room temperature, and demonstrates the strong solvency of long-chain lithium polysulfides in three solutions. However, in the pure solvent and $0.1 \mathrm{M}$ solutions the dissolved S species diffuse even more slowly not only when compared with $1 \mathrm{M}$, but also with $3 \mathrm{M}$ electrolytes (Fig. 5), which means the polysulfide shuttles effects are largely reduced in the $0.1 \mathrm{M}$ electrolyte. More LiTFSI salt in $1 \mathrm{M}$ electrolyte aggravates the diffusion of polysulfides. This unexpected behavior (suppressed polysulfide diffusion/shuttle) is correlated with a significantly more pronounced aggregation of $\mathrm{Li}_{2} \mathrm{~S}_{2}$ and their mixtures with $\mathrm{Li}_{2} \mathrm{~S}_{4}$ observed in MD simulations of dilute electrolytes (Fig. 4). Slower polysulfides diffusion lead to better cycle stability (Fig. If ang g), smooth surface morphology of cycled electrodes (Fig. $2 b$ and d) and no change of charge-transfer resistance during cycling (Fig. 2f) in the $0.1 \mathrm{M}$ electrolyte.

In summary, we have demonstrated an unexpected ability of the dilute electrolyte $\left(0.1 \mathrm{~mol} \mathrm{~L}^{-1}\right.$ of LiTFSI in DME/DOL with 1 wt.\% $\left.\mathrm{LiNO}_{3}\right)$ to offer outstanding performance in high-energy Li-S batteries. Due to very low viscosity, excellent wetting on sulfur cathodes and dramatically reduced shortchain polysulfide dissolution and polysulfides shuttle effects, the carbon-sulfur cathodes displayed much higher rate capability and better cell stability (in terms of both capacity retention and the lack of growth in charge transfer resistance) in the $0.1 \mathrm{M}$ electrolyte than in standard $1 \mathrm{M}$ or concentrated electrolytes for medium $\left(2 \mathrm{mg}_{\mathrm{s}} \cdot \mathrm{cm}^{-2}\right)$ and high-loading $\left(3.8-5.2 \mathrm{mg}_{\mathrm{s}} \cdot \mathrm{cm}^{-2}\right)$ electrodes. Postmortem analyses and lithium polysulfide dissolution experiments confirmed significantly reduced shuttle of long-chain polysulfides in $0.1 \mathrm{M}$ electrolyte. MD 
simulations shine more light on the superior performance of dilute LiTFSI-based electrolytes: at low salt concentrations $(0.1 \mathrm{M} \mathrm{LiTFSI}) \mathrm{Li}^{+}$cations bridge $\mathrm{Li}_{2} \mathrm{~S}_{2}$ into large phase-separated domains preventing short-chain polysulfide dissolution into the bulk of the electrolyte; aggregations of $\mathrm{Li}_{2} \mathrm{~S}_{4}$ via participation in the $\mathrm{Li}_{2} \mathrm{~S}_{2}$ aggregates (forming $\mathrm{Li}_{2} \mathrm{~S}_{2}-\mathrm{Li}_{2} \mathrm{~S}_{4}$ clusters) lead to slowing down of not only $\mathrm{Li}_{2} \mathrm{~S}_{2}$ diffusion but also $\mathrm{Li}_{2} \mathrm{~S}_{4}$ diffusion at $0.1 \mathrm{M}$ (vs. $1 \mathrm{M} \mathrm{LiTFSI}$ ). Therefore, dilute electrolytes may become more suitable for the nextgeneration Li-S batteries and possibly other conversion-type cathode chemistries. We call for future studies of dilute and ultra-dilute electrolytes on high sulfur loadings and low E/S ratios to be carried out in Li-S pouch cells.

\section{ASSOCIATED CONTENT}

The Supporting Information is available free of charge. It mainly includes the experimental details, characterizations, details of simulation, and electrochemical characterizations.

\section{AUTHOR INFORMATION \\ * Corresponding Authors \\ Email: feixiang.wu@csu.edu.cn \\ Email: yanyumse@ustc.edu.cn \\ Email:yushin@gatech.edu}

\section{Notes}

The authors declare no competing interests.

\section{Author Contributions}

F.W., Y.Y., and G.Y. conceived the idea. F.W. and F.C. carried out the materials synthesis, characterization, electrochemical studies and wrote the original draft. M.S. synthesized the carbon capsule nanopowder. O.B. did the simulation part. All the authors discussed the results and contributed to the writing of manuscript.

\section{Acknowledgements}


This work was largely supported by the National Key R\&D Research Program of China (No. 2018YFB0905400), the Innovation-Driven Project of Central South University (No.2019CX033), the National Key R\&D Research Program of China (No. 2018YFB0905400), the National Natural Science Foundation of China (Nos. U1910210, 51904344, 51925207, 51872277), and the DNL cooperation Fund, CAS (DNL180310), and the Fundamental Research Funds for the Central Universities (Wk2060140026, WK2060000009). The modeling part of the work performed at ARL was supported as part of the Joint Center for Energy Storage Research (JCESR), an Energy Innovation Hub funded by the U.S. Department of Energy, Office of Science, Basic Energy Sciences. 


\section{Figures}

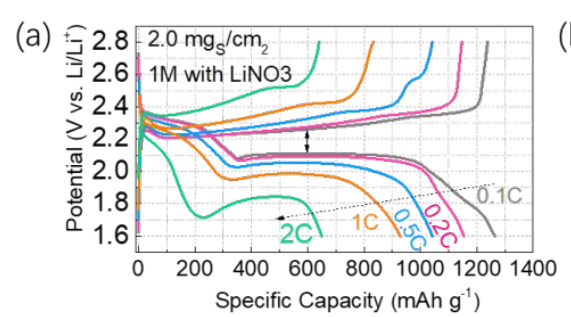

(d)

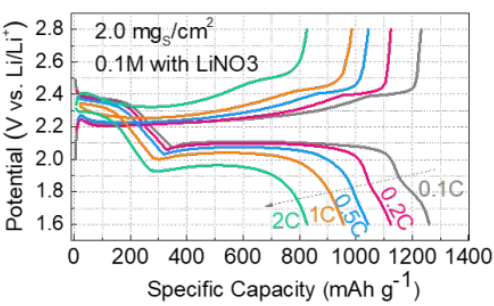

(g)

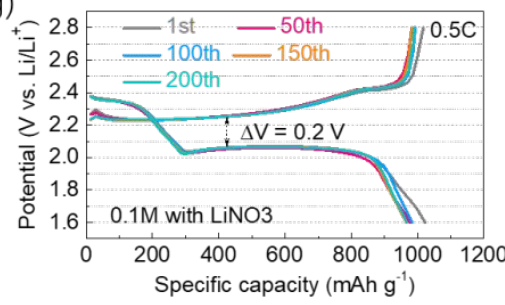

(b)

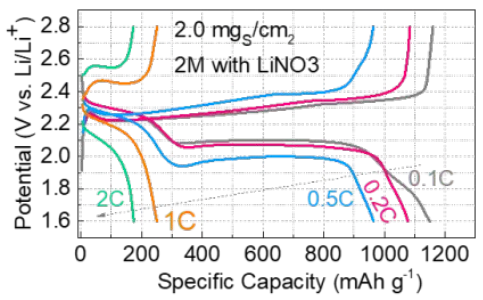

(e)

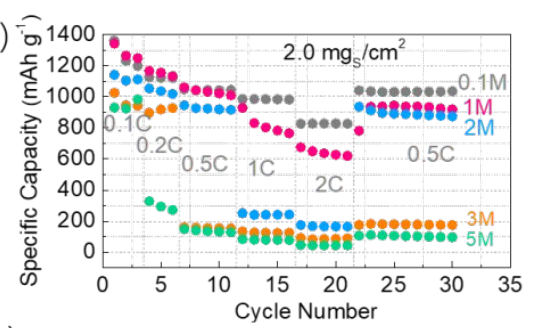

(h)

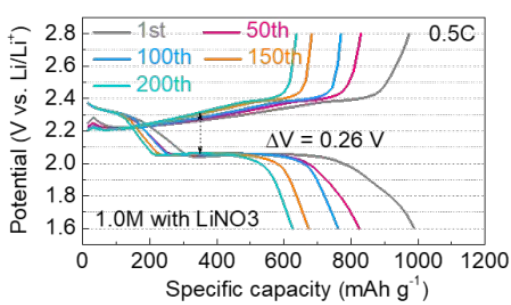

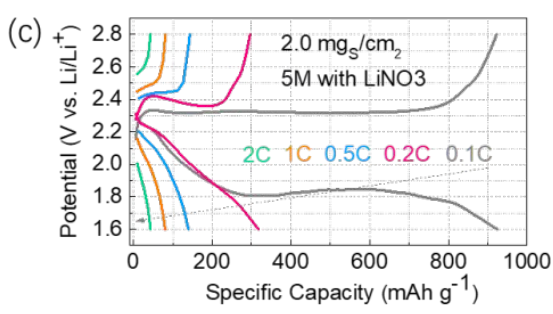

(f)

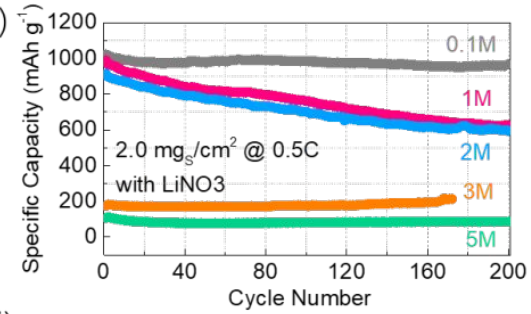

(i)

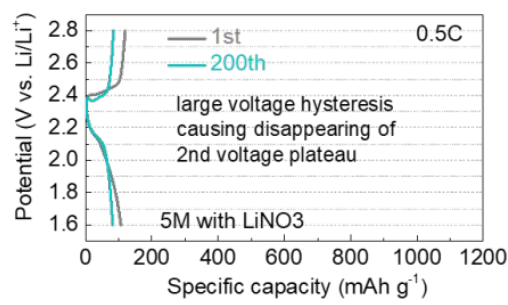

Figure 1. Electrochemical characterizations of CC-S cathode in electrolytes with various salt concentrations: voltage profiles of $C C$-S cathode at different $C$ rates in (a) $1 \mathrm{M}$, (b) $2 \mathrm{M}$, (c) $5 \mathrm{M}$ and (d) $0.1 \mathrm{M}$ electrolytes; (e) discharge capacity at different $\mathrm{C}$-rates of the CC-S sample in electrolytes with different concentrations; (f) cycling performance at $\mathrm{C} / 2$ of the CC-S cathode in produced electrolytes from $0.1 \mathrm{M}$ to $5 \mathrm{M}$, displaying higher rate and more stable cycling performance in dilute $(0.1 \mathrm{M})$ electrolyte; Changes in charge-discharge profiles at $0.5 \mathrm{C}$ in $(\mathrm{g}) 0.1 \mathrm{M}$, (h) $1 \mathrm{M}$ and (i) $5 \mathrm{M}$ electrolytes. All electrolytes comprised 1 wt.\% $\mathrm{LiNO}_{3}$ additives. 

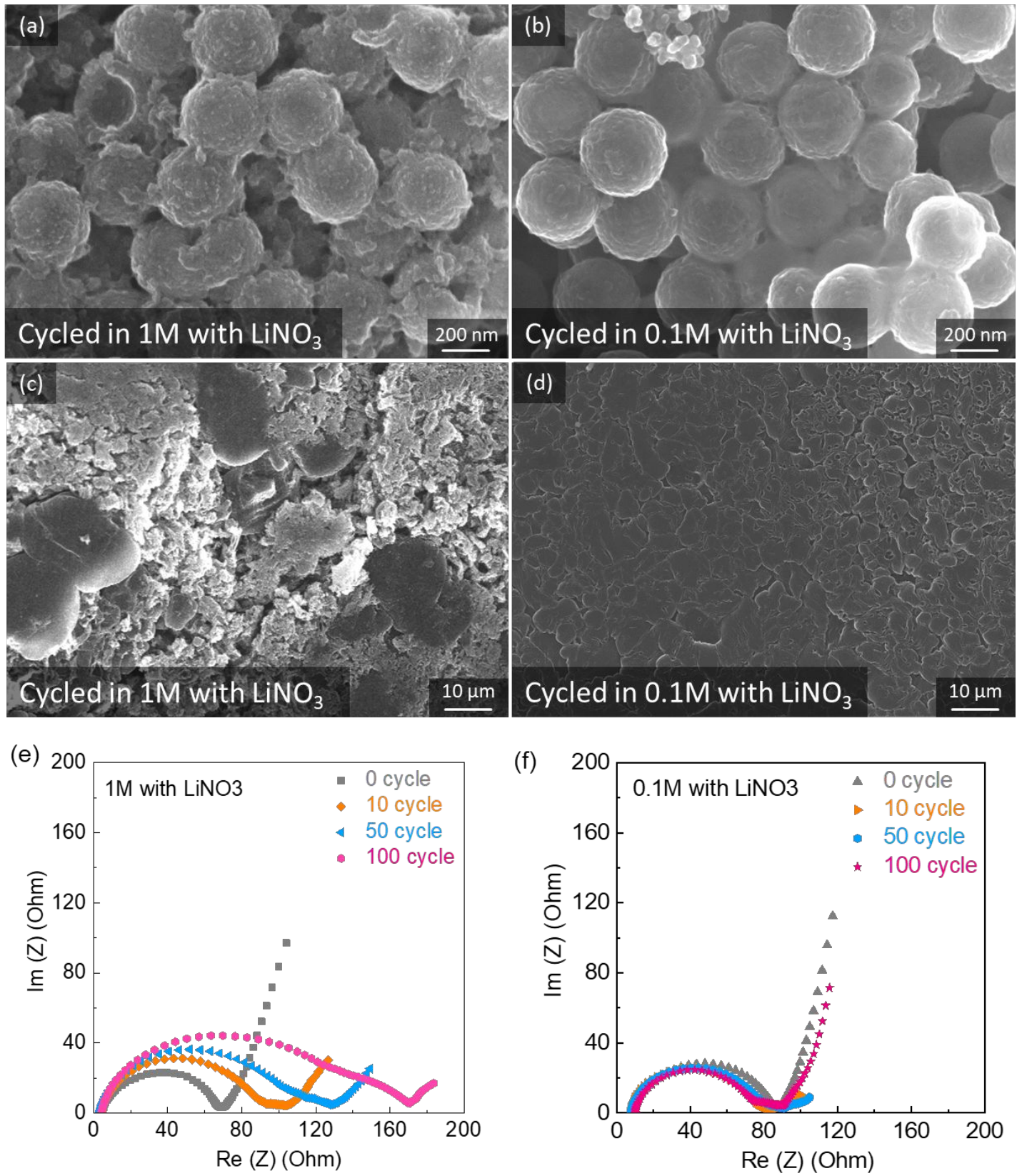

Figure 2. Post-mortem analysis of cycled electrodes and EIS changes revealed a drastic effect of ultra-dilute electrolyte in Li-S batteries: SEM images of (a) CC-S cathode and (c) $\mathrm{Li}$ anode after 200cycles in $1 \mathrm{M}$ electrolyte as a benchmark; SEM images of cycled (b) CC-S cathode and (d) Li anode after 200 cycles in $0.1 \mathrm{M}$ electrolyte; the EIS changes of cells within 100 cycles in both (e) $1 \mathrm{M}$ and (f) $0.1 \mathrm{M}$ electrolytes. Nearly no changes in the cathode, a densesmooth surface morphology with large grains and no visible Li dendrites on the $\mathrm{Li}$ anode, and nearly no charge-transfer resistance increase in the $0.1 \mathrm{M}$ electrolyte. 
(a)

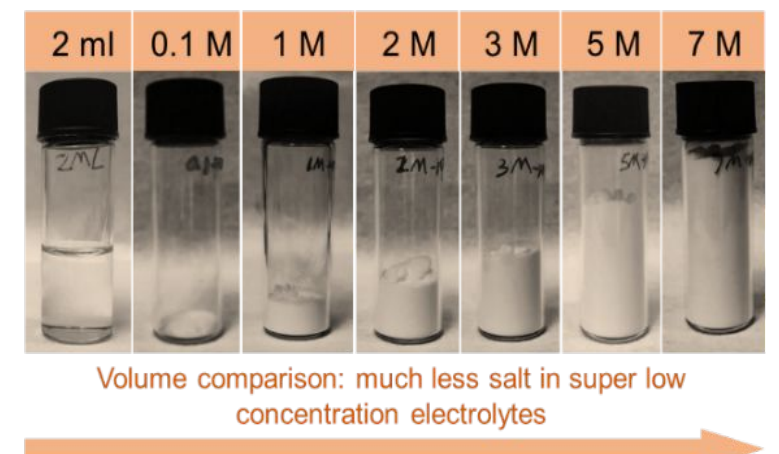

(c)

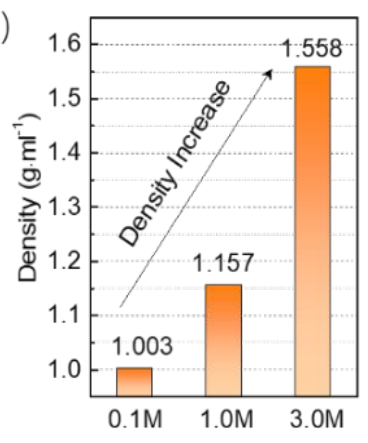

(d)

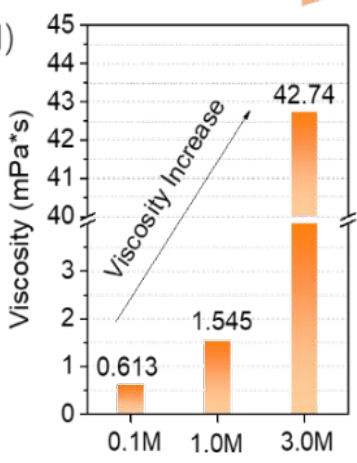

(b)

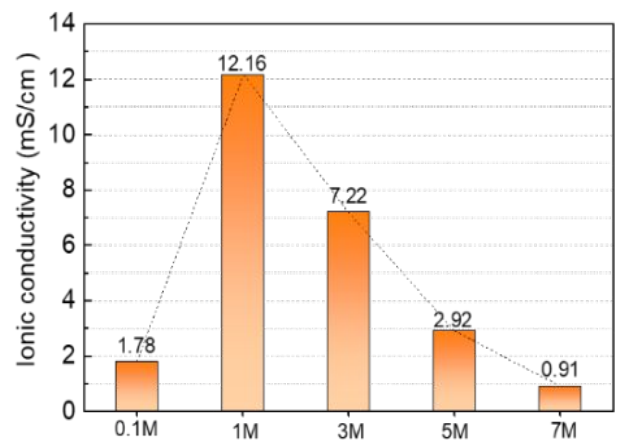

(e)

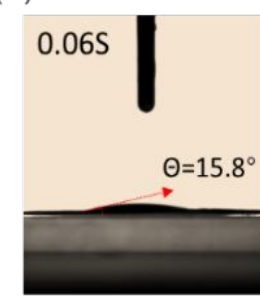

Ultra-dilute

$0.1 \mathrm{M}$

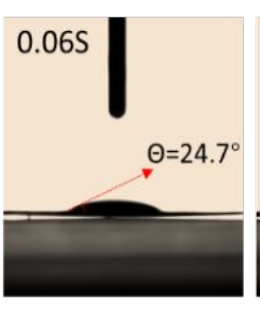

Standard $1.0 \mathrm{M}$

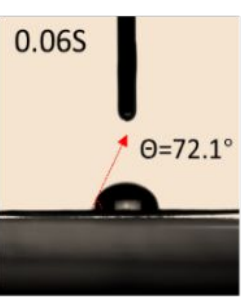

Concentrated

$3.0 \mathrm{M}$

Figure 3. Comparison studies of physical properties among ultra-dilute, standard and concentrated electrolytes: (a) the digital photos of $2 \mathrm{ml}$ pure solvent and different volumes of $\mathrm{Li}$ salt corresponding to different electrolyte concentrations for $2 \mathrm{ml}$ liquid in the electrolyte; (b) ionic conductivity of $0.1,1,2$, 3 , and $5 \mathrm{M}$ electrolytes (note good agreement with MD predictions shown in Table S2); (c) density and (d) viscosity of electrolytes with different molarities; (e) digital photographs of the different molarity electrolyte droplet contact angles on CC-S cathode, showing much less salt, lower density, lower viscosity and better wetting properties of a dilute $(0.1 \mathrm{M})$ electrolyte. 
(a) $0.5 \mathrm{M} \mathrm{Li}_{2} \mathrm{~S}_{2}$ in $0.1 \mathrm{M} \mathrm{LiTFSI}$

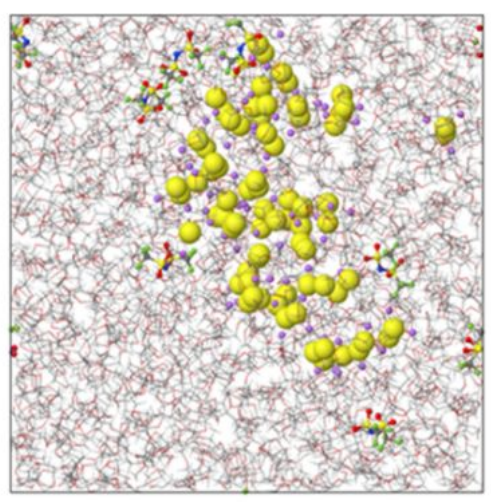

(d)

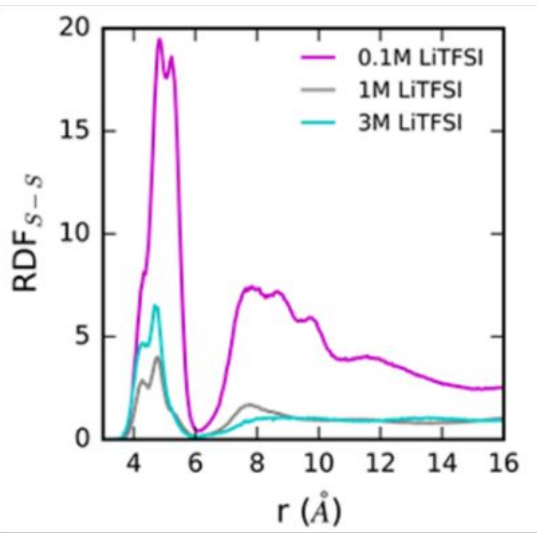

(b) $0.5 \mathrm{M} \mathrm{Li} \mathrm{S}_{2}$ in $1 \mathrm{M} \mathrm{LiTFSI}$

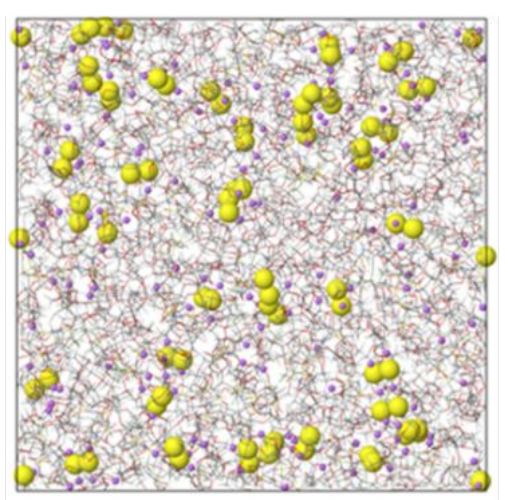

(e) $0.24 \mathrm{M} \mathrm{Li} \mathrm{S}_{2}+0.24 \mathrm{M} \mathrm{Li} \mathrm{S}_{4}$ in $0.1 \mathrm{M}$ LiTFSI

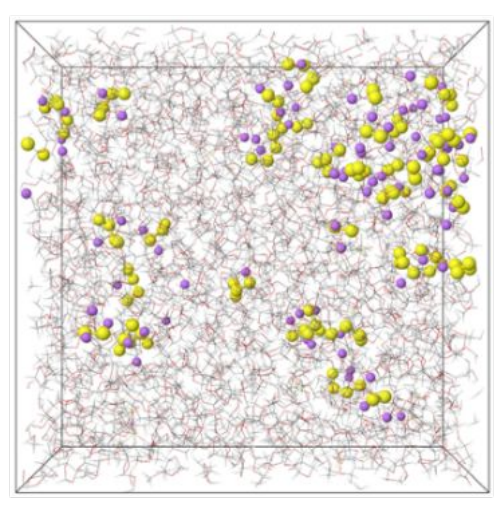

(c) $0.5 \mathrm{M} \mathrm{Li} \mathrm{Li}_{2}$ in $3 \mathrm{M} \mathrm{LiTFSI}$

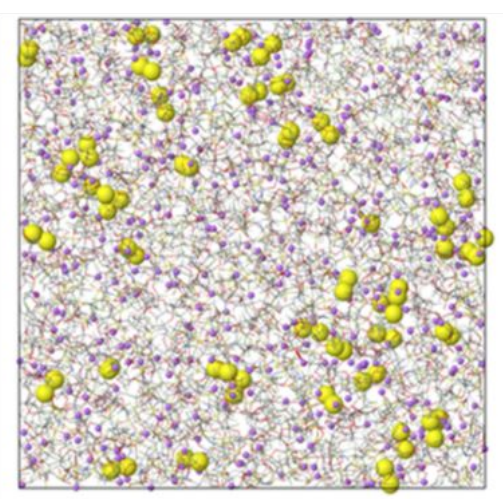

(f)

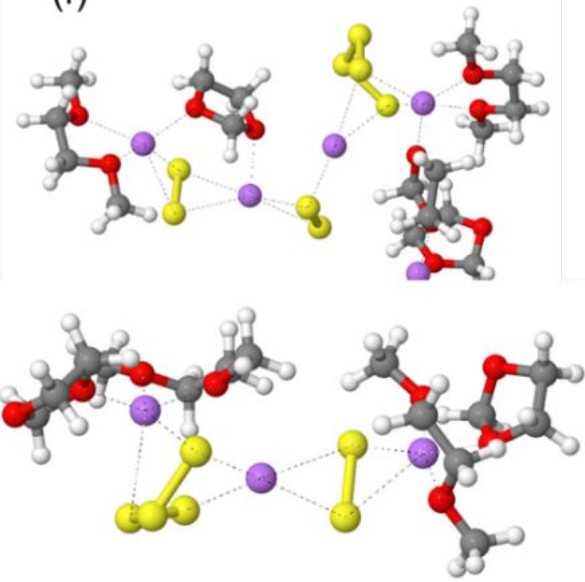

Figure 4. Snapshots of MD simulations boxes highlighting (a-c) $S_{2}$ anions and (e) $S_{2}$ and $S_{4}$ anions (shown in yellow), solvent and TFSI- are shown as a wire frame; (d) intermolecular radial distribution functions (RDFs) of S-S from $S_{2}$ anions corresponding to (a-c), (f) the $\mathrm{Li}_{2} \mathrm{~S}_{2}-\mathrm{Li}_{2} \mathrm{~S}_{4}$ clusters from simulations (e). 


\section{Mixture $\left(\mathrm{Li}_{2} \mathrm{~S}+\mathrm{S}\right)$ in different solutions}

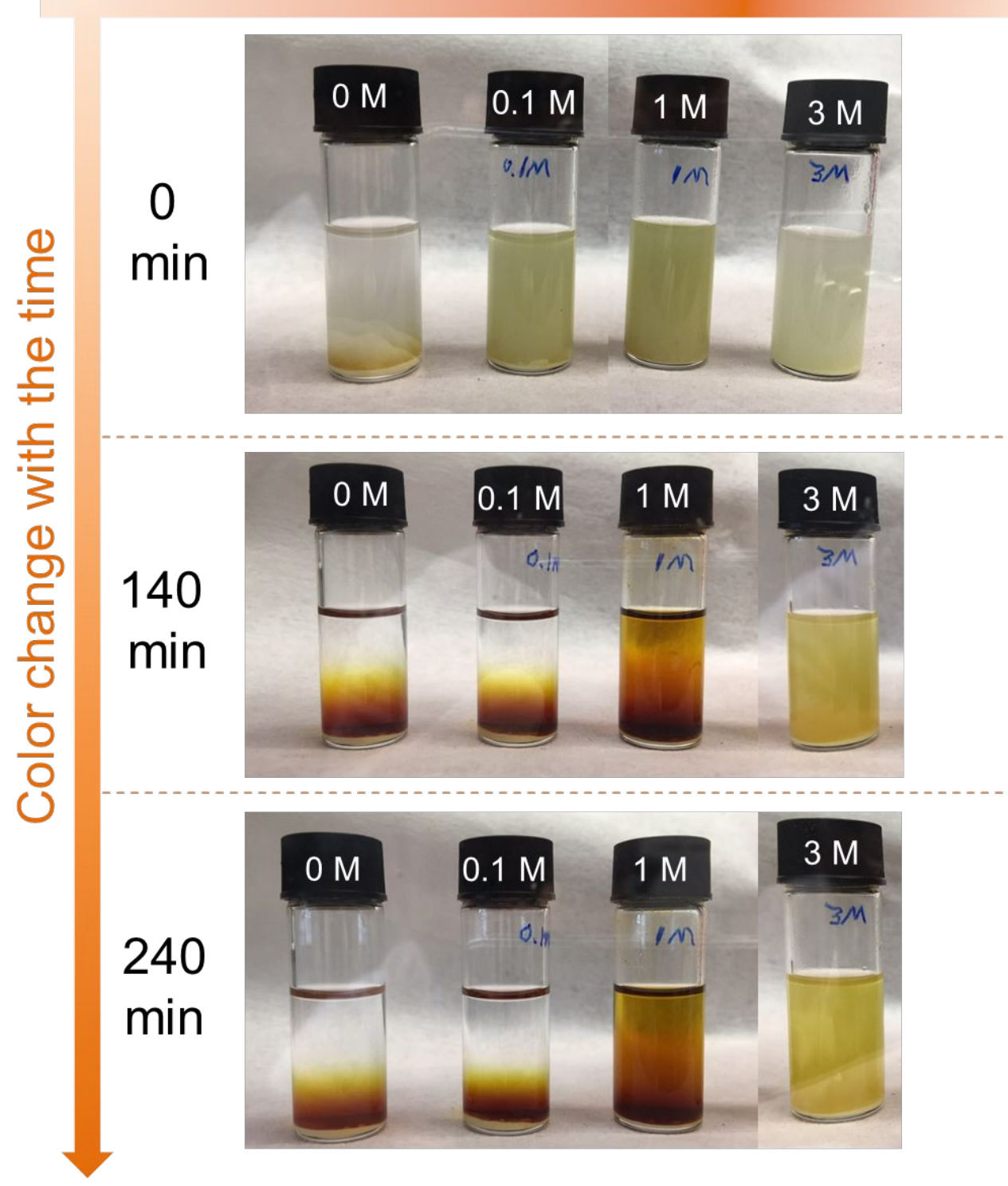

Figure 5. Lithium polysulfide dissolution experiments: the color changes of four samples with different salt (LiTFSI) concentrations containing the same amount of $\mathrm{Li}_{2} \mathrm{~S}$ and $\mathrm{S}$ mixtures $\left(\mathrm{Li}_{2} \mathrm{~S}: \mathrm{S}=1: 3 \mathrm{~mol} / \mathrm{mol}\right)$ were recorded by digital camera with time (without any shaking). The mass of powder was calculated by an ideal formation of $0.2 \mathrm{~mol} \mathrm{~L}^{-1} \mathrm{Li}_{2} \mathrm{~S}_{4}$ in $3 \mathrm{ml}$ of liquid. The produced samples are: pure solvent (OM), $0.1 \mathrm{~mol}$ LiTFSI per I mol solvent (here we call it $0.1 \mathrm{M}), 1 \mathrm{~mol}$ LiTFSI per I solvent (1M), and 3 mol LiTFSI per I mol solvent (3M), respectively. 


\section{REFERENCES}

(1) Choi, J. W.; Aurbach, D. Promise and Reality of Post-Lithium-Ion Batteries with High Energy Densities. Nat. Rev. Mater. 2016, 1, 16013.

(2) Wu, F.; Yushin, G. Conversion Cathodes for Rechargeable Lithium and Lithium-Ion Batteries. Energy Environ. Sci. 2017, 10, 435-459.

(3) Wang, L.; Wu, Z.; Zou, J.; Gao, P.; Niu, X.; Li, H.; Chen, L. Li-Free Cathode Materials for High Energy Density Lithium Batteries. Joule 2019, 3, 2086-2102.

(4) Wang, R.; Cui, W.; Chu, F.; Wu, F. Lithium Metal Anodes: Present and Future. J. Energy Chem. 2020, 48, 145-159.

(5) Turcheniuk, K.; Bondarev, D.; Singhal, V.; Yushin, G. Ten Years Left to Redesign LithiumIon Batteries. Nature 2018, 559, 467-470.

(6) Nitta, N.; Wu, F.; Lee, J. T.; Yushin, G. Li-lon Battery Materials: Present and Future. Mater. Today 2015, 18, 252-264.

(7) Wu, F.; Borodin, O.; Yushin, G. In Situ Surface Protection for Enhancing Stability and Performance of Conversion-Type Cathodes. MRS Energy \& Sustainability 2017, 4, E9.

(8) Wu, F.; Maier, J.; Yu, Y. Guidelines and Trends for Next-Generation Rechargeable Lithium and Lithium-Ion Batteries. Chem. Soc. Rev. 2020, 49, 1569-1614.

(9) Sun, K.; Li, N.; Su, D.; Gan, H. Electrolyte Concentration Effect on Sulfur Utilization of LiS Batteries. J. Electrochem. Soc. 2019, 166, A50-A58.

(10) Zhang, S. S. Liquid Electrolyte Lithium/Sulfur Battery: Fundamental Chemistry, Problems, and Solutions. J. Power Sources 2013, 231, 153-162.

(11) Rajput, N. N.; Murugesan, V.; Shin, Y.; Han, K. S.; Lau, K. C.; Chen, J.; Liu, J.; Curtiss, L. A.; Mueller, K. T.; Persson, K. A. Elucidating the Solvation Structure and Dynamics of Lithium Polysulfides Resulting from Competitive Salt and Solvent Interactions. Chem. Mater. 2017, 29, 3375-3379.

(12) Manthiram, A.; Fu, Y.; Chung, S.-H.; Zu, C.; Su, Y.-S. Rechargeable Lithium-Sulfur Batteries. Chem. Rev. 2014, 114, 11751-11787.

(13) Li, M.; Zhang, Y.; Bai, Z.; Liu, W. W.; Liu, T.; Gim, J.; Jiang, G.; Yuan, Y.; Luo, D.; Feng, K.; Yassar, R. S.; Wang, X.; Chen, Z.; Lu, J. A Lithium-Sulfur Battery using a 2D Current Collector Architecture with a Large-Sized Sulfur Host Operated under High Areal Loading and Low E/S Ratio. Adv. Mater. 2018, 30, 1804271.

(14) Emerce, N. B.; Eroglu, D. Effect of Electrolyte-to-Sulfur Ratio in the Cell on the Li-S Battery Performance. J. Electrochem. Soc. 2019, 166, A1490-A1500.

(15) Zhang, G.; Peng, H.-J.; Zhao, C.-Z.; Chen, X.; Zhao, L.-D.; Li, P.; Huang, J.-Q.; Zhang, Q. The Radical Pathway Based on a Lithium-Metal-Compatible High-Dielectric Electrolyte for Lithium-Sulfur Batteries. Angew. Chem. Int. Ed. 2018, 57, 16732-16736.

(16) Zhang, L.; Liu, D.; Muhammad, Z.; Wan, F.; Xie, W.; Wang, Y.; Song, L.; Niu, Z.; Chen, J. Single Nickel Atoms on Nitrogen-Doped Graphene Enabling Enhanced Kinetics of LithiumSulfur Batteries. Adv. Mater. 2019, 31, 1903955.

(17) Wu, F.; Chen, S.; Srot, V.; Huang, Y.; Sinha Shyam, K.; Aken Peter, A.; Maier, J.; Yu, Y. A Sulfur-Limonene-Based Electrode for Lithium-Sulfur Batteries: High-Performance by Self- 
Protection. Adv. Mater. 2018, 30, 1706643.

(18) Liu, X.; Huang, J.-Q.; Zhang, Q.; Mai, L. Nanostructured Metal Oxides and Sulfides for Lithium-Sulfur Batteries. Adv. Mater. 2017, 29, 1601759.

(19) Wu, F.; Lee, J. T.; Fan, F.; Nitta, N.; Kim, H.; Zhu, T.; Yushin, G. A Hierarchical ParticleShell Architecture for Long-Term Cycle Stability of $\mathrm{Li}_{2} \mathrm{~S}$ Cathodes. Adv. Mater. 2015, 27, 55795586.

(20) Du, Z.; Chen, X.; Hu, W.; Chuang, C.; Xie, S.; Hu, A.; Yan, W.; Kong, X.; Wu, X.; Ji, H.; Wan, L.-J. Cobalt in Nitrogen-Doped Graphene as Single-Atom Catalyst for High-Sulfur Content Lithium-Sulfur Batteries. J. Am. Chem. Soc. 2019, 141, 3977-3985.

(21) Wu, F.; Pollard, T. P.; Zhao, E.; Xiao, Y.; Olguin, M.; Borodin, O.; Yushin, G. Layered $\mathrm{LiTiO}_{2}$ for the Protection of $\mathrm{Li}_{2} \mathrm{~S}$ Cathodes Against Dissolution: Mechanisms of the Remarkable Performance Boost. Energy Environ. Sci. 2018, 11, 807-817.

(22) Wu, F.; Lv, H.; Chen, S.; Lorger, S.; Srot, V.; Oschatz, M.; van Aken, P. A.; Wu, X.; Maier, J.; Yu, Y. Natural Vermiculite Enables High-Performance in Lithium-Sulfur Batteries via Electrical Double Layer Effects. Adv. Funct. Mater. 2019, 29, 1902820.

(23) Lin, Z.; Liang, C. Lithium-Sulfur Batteries: From Liquid to Solid Cells. J. Mater. Chem. A 2015, 3, 936-958.

(24) Judez, X.; Martinez-lbañez, M.; Santiago, A.; Armand, M.; Zhang, H.; Li, C. Quasi-SolidState Electrolytes for Lithium Sulfur Batteries: Advances and Perspectives. J. Power Sources 2019, 438, 226985.

(25) Wu, F.; Lee, J. T.; Nitta, N.; Kim, H.; Borodin, O.; Yushin, G. Lithium lodide as a Promising Electrolyte Additive for Lithium-Sulfur Batteries: Mechanisms of Performance Enhancement. Adv. Mater. 2015, 27, 101-108.

(26) Wu, F.; Zhao, E.; Gordon, D.; Xiao, Y.; Hu, C.; Yushin, G. Infiltrated Porous Polymer Sheets as Free-Standing Flexible Lithium-Sulfur Battery Electrodes. Adv. Mater. 2016, 28, 6365-6371.

(27) Choudhury, S.; Ebert, T.; Windberg, T.; Seifert, A.; Göbel, M.; Simon, F.; Formanek, P.; Stamm, M.; Spange, S.; Ionov, L. Hierarchical Porous Carbon Cathode for Lithium-Sulfur Batteries Using Carbon Derived from Hybrid Materials Synthesized by Twin Polymerization. Part. Part. Syst. Charact. 2018, 35, 1800364.

(28) Shi, H.; Niu, S.; Lv, W.; Zhou, G.; Zhang, C.; Sun, Z.; Li, F.; Kang, F.; Yang, Q.-H. Easy Fabrication of Flexible and Multilayer Nanocarbon-Based Cathodes with a High Unreal Sulfur Loading by Electrostatic Spraying for Lithium-Sulfur Batteries. Carbon 2018, 138, 18-25.

(29) Wu, F.; Lee, J. T.; Magasinski, A.; Kim, H.; Yushin, G. Solution-Based Processing of Graphene-Li $\mathrm{i}_{2} \mathrm{~S}$ Composite Cathodes for Lithium-Ion and Lithium-Sulfur Batteries. Part. Part. Syst. Charact. 2014, 31, 639-644.

(30) Borchardt, L.; Oschatz, M.; Kaskel, S. Carbon Materials for Lithium Sulfur Batteries-Ten Critical Questions. Chem. Eur. J. 2016, 22, 7324-7351.

(31) Strubel, P.; Thieme, S.; Biemelt, T.; Helmer, A.; Oschatz, M.; Brückner, J.; Althues, H.; Kaskel, S. ZnO Hard Templating for Synthesis of Hierarchical Porous Carbons with Tailored Porosity and High Performance in Lithium-Sulfur Battery. Adv. Funct. Mater. 2015, 25, $287-$ 297.

(32) Yan, R.; Oschatz, M.; Wu, F. Towards Stable Lithium-Sulfur Battery Cathodes by Combining Physical and Chemical Confinement of Polysulfides in Core-Shell Structured 
Nitrogen-Doped Carbons. Carbon 2020, 161, 162-168.

(33) Sun, Z.; Zhang, J.; Yin, L.; Hu, G.; Fang, R.; Cheng, H.-M.; Li, F. Conductive Porous Vanadium Nitride/Graphene Composite as Chemical Anchor of Polysulfides for Lithium-Sulfur Batteries. Nat. Commun. 2017, 8, 14627.

(34) Gupta, A.; Bhargav, A.; Manthiram, A. Highly Solvating Electrolytes for Lithium-Sulfur Batteries. Adv. Energy Mater. 2019, 9, 1803096.

(35) Umeshbabu, E.; Zheng, B.; Yang, Y. Recent Progress in All-Solid-State Lithium-Sulfur Batteries Using High Li-lon Conductive Solid Electrolytes. Electrochem. Energy Rev. 2019, 2, 199-230.

(36) Lei, D.; Shi, K.; Ye, H.; Wan, Z.; Wang, Y.; Shen, L.; Li, B.; Yang, Q.-H.; Kang, F.; He, Y.B. Progress and Perspective of Solid-State Lithium-Sulfur Batteries. Adv. Funct. Mater. 2018, 28, 1707570.

(37) Markevich, E.; Salitra, G.; Rosenman, A.; Talyosef, Y.; Chesneau, F.; Aurbach, D. Fluoroethylene Carbonate as an Important Component in Organic Carbonate Electrolyte Solutions for Lithium Sulfur Batteries. Electrochem. Commun. 2015, 60, 42-46.

(38) Kim, H.; Wu, F.; Lee, J. T.; Nitta, N.; Lin, H.-T.; Oschatz, M.; Cho, W. I.; Kaskel, S.; Borodin, O.; Yushin, G. In Situ Formation of Protective Coatings on Sulfur Cathodes in Lithium Batteries with LiFSI-Based Organic Electrolytes. Adv. Energy Mater. 2015, 5, 1401792.

(39) Wu, F.; Thieme, S.; Ramanujapuram, A.; Zhao, E.; Weller, C.; Althues, H.; Kaskel, S.; Borodin, O.; Yushin, G. Toward In-Situ Protected Sulfur Cathodes by Using Lithium Bromide and Pre-Charge. Nano Energy 2017, 40, 170-179.

(40) Hu, C.; Chen, H.; Shen, Y.; Lu, D.; Zhao, Y.; Lu, A.-H.; Wu, X.; Lu, W.; Chen, L. In Situ Wrapping of the Cathode Material in Lithium-Sulfur Batteries. Nat. Commun. 2017, 8, 479.

(41) Yang, T.; Qian, T.; Liu, J.; Xu, N.; Li, Y.; Grundish, N.; Yan, C.; Goodenough, J. B. A New Type of Electrolyte System To Suppress Polysulfide Dissolution for Lithium-Sulfur Battery. ACS Nano 2019, 13, 9067-9073.

(42) Pan, H.; Han, K. S.; Vijayakumar, M.; Xiao, J.; Cao, R.; Chen, J.; Zhang, J.; Mueller, K. T.; Shao, Y.; Liu, J., Ammonium Additives to Dissolve Lithium Sulfide through Hydrogen Binding for High-Energy Lithium-Sulfur Batteries. ACS Appl. Mater. Inter. 2017, 9, 4290-4295.

(43) Cheng, Q.; Xu, W.; Shiyi, Q.; Das, S.; Jin, T.; Li, A.; Li, A.; Qie, B.; Yao, P.; Zhai, H.; Shi, C.; Yong, X.; Yang, Y., Full Dissolution of $\mathrm{Li}_{2} \mathrm{~S}_{8}$ to $\mathrm{Li}_{2} S$ in Safe Eutectic Solvent for Rechargeable Lithium-Sulfur Batteries. Angew. Chem. Int. Ed. 2019, 58, 5557-5561.

(44) Shyamsunder, A.; Beichel, W.; Klose, P.; Pang, Q.; Scherer, H.; Hoffmann, A.; Murphy, G. K.; Krossing, I.; Nazar, L. F. Inhibiting Polysulfide Shuttle in Lithium-Sulfur Batteries through Low-Ion-Pairing Salts and a Triflamide Solvent. Angew. Chem. Int. Ed. 2017, 56, 6192-6197.

(45) Rohde, M.; Eiden, P.; Leppert, V.; Schmidt, M.; Garsuch, A.; Semrau, G.; Krossing, I. $\mathrm{Li}\left[\mathrm{B}\left(\mathrm{OCH}_{2} \mathrm{CF}_{3}\right)_{4}\right]$ : Synthesis, Characterization and Electrochemical Application as a Conducting Salt for LiSB Batteries. Chemphyschem 2015, 16, 666-675.

(46) Lee, J. T.; Zhao, Y.; Thieme, S.; Kim, H.; Oschatz, M.; Borchardt, L.; Magasinski, A.; Cho, W.-I.; Kaskel, S.; Yushin, G. Sulfur-Infiltrated Micro- and Mesoporous Silicon Carbide-Derived Carbon Cathode for High-Performance Lithium Sulfur Batteries. Adv. Mater. 2013, 25, 45734579 .

(47) Suo, L.; Hu, Y.-S.; Li, H.; Armand, M.; Chen, L. A New Class of Solvent-in-Salt Electrolyte for High-Energy Rechargeable Metallic Lithium Batteries. Nat. Commun. 2013, 4, 1481. 
(48) Nakanishi, A.; Ueno, K.; Watanabe, D.; Ugata, Y.; Matsumae, Y.; Liu, J.; Thomas, M. L.; Dokko, K.; Watanabe, M. Sulfolane-Based Highly Concentrated Electrolytes of Lithium Bis(trifluoromethanesulfonyl)amide: Ionic Transport, Li-Ion Coordination, and Li-S Battery Performance. J. Phys. Chem. C 2019, 123, 14229-14238.

(49) Yamada, Y.; Wang, J.; Ko, S.; Watanabe, E.; Yamada, A. Advances and Issues in Developing Salt-Concentrated Battery Electrolytes. Nature Energy 2019, 4, 269-280.

(50) Hwang, J.-Y.; Kim, H. M.; Sun, Y.-K. Controlling the Wettability between Freestanding Electrode and Electrolyte for High Energy Density Lithium-Sulfur Batteries. J. Electrochem. Soc. 2018, 165, A5006-A5013.

(51) Jayaprakash, N.; Shen, J.; Moganty, S. S.; Corona, A.; Archer, L. A. Porous Hollow Carbon@Sulfur Composites for High-Power Lithium-Sulfur Batteries. Angew. Chem. Int. Ed. 2011, 50, 5904-5908.

(52) Huang, S.; Guan, R.; Wang, S.; Xiao, M.; Han, D.; Sun, L.; Meng, Y. Polymers for High Performance Li-S Batteries: Material Selection and Structure Design. Prog. Polym. Sci. 2019, 89, $19-60$.

(53) Razaq, R.; Sun, D.; Wang, J.; Xin, Y.; Abbas, G.; Zhang, J.; Li, Q.; Huang, T.; Zhang, Z.; Huang, Y. Ultrahigh Sulfur Loading in $\mathrm{ZnS}_{1-\mathrm{x}} / \mathrm{rGO}$ through In Situ Oxidation-Refilling Route for High-Performance Li-S Batteries. J. Power Sources 2019, 414, 453-459.

(54) Xu, K. Nonaqueous Liquid Electrolytes for Lithium-Based Rechargeable Batteries. Chem. Rev. 2004, 104, 4303-4418.

(55) Li, G.; Wang, S.; Zhang, Y.; Li, M.; Chen, Z.; Lu, J. Revisiting the Role of Polysulfides in Lithium-Sulfur Batteries. Adv. Mater. 2018, 30, 1705590.

(56) Shen, C.; Xie, J.; Zhang, M.; Andrei, P.; Hendrickson, M.; Plichta, E. J.; Zheng, J. P. Understanding the Role of Lithium Polysulfide Solubility in Limiting Lithium-Sulfur Cell Capacity. Electrochim. Acta 2017, 248, 90-97.

(57) Son, Y.; Lee, J.-S.; Son, Y.; Jang, J.-H.; Cho, J. Recent Advances in Lithium Sulfide Cathode Materials and Their Use in Lithium Sulfur Batteries. Adv. Energy Mater. 2015, 5, 1500110. 


\section{ToC}

10

11
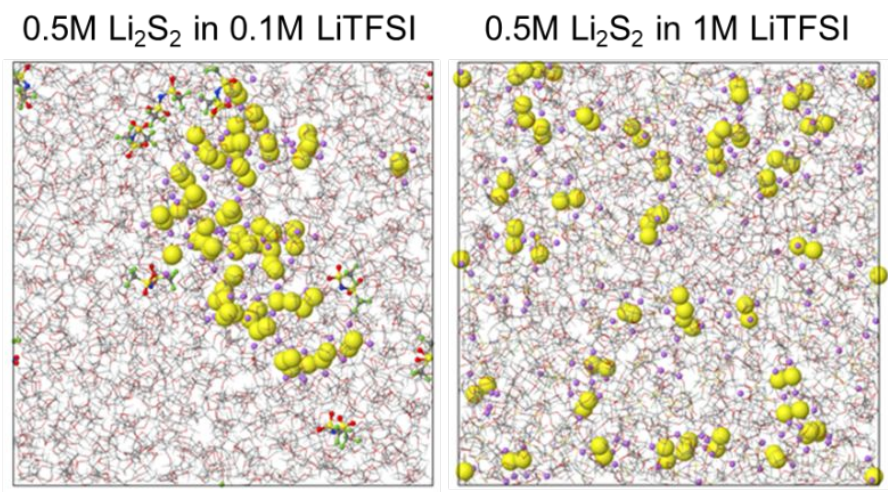